\title{
Laboratory testing of extravascular body fluids in Croatia: a survey of the Working group for extravascular body fluids of the Croatian Society of Medical Biochemistry and Laboratory Medicine
}

\author{
Lara Milevoj Kopcinovic*1 ${ }^{* 1}$ Zeljka Vogrinc ${ }^{2}$, Irena Kocijann ${ }^{3}$, Jelena Culej $^{4}$, Merica Aralica ${ }^{5}$, Anja Jokic ${ }^{6}$, Dragana Antoncic ${ }^{5}$, Marija Bozovic ${ }^{1}$ \\ 'University Department of Chemistry, Medical School University Hospital Sestre Milosrdnice, Zagreb, Croatia \\ ${ }^{2}$ Department of Laboratory Diagnostics, University Hospital Centre Zagreb, Zagreb, Croatia \\ ${ }^{3}$ Medical Biochemistry Laboratory, General hospital Varaždin, Varaždin, Croatia \\ ${ }^{4}$ Department of Transfusiology and Hemostasis, Medical School University Hospital Sestre Milosrdnice, Zagreb, Croatia \\ ${ }^{5}$ Clinical Department of Laboratory Diagnostics, Clinical Hospital Centre Rijeka, Rijeka, Croatia \\ ${ }^{6}$ Medical Biochemistry Laboratory, Primary Health Care Centre Zagreb - East, Zagreb, Croatia \\ ${ }^{*}$ Corresponding author: laramilevoj@gmail.com
}

\begin{abstract}
Introduction: We hypothesized that extravascular body fluid (EBF) analysis in Croatia is not harmonized and aimed to investigate preanalytical, analytical and postanalytical procedures used in EBF analysis in order to identify key aspects that should be addressed in future harmonization attempts.

Materials and methods: An anonymous online survey created to explore laboratory testing of EBF was sent to secondary, tertiary and private health care Medical Biochemistry Laboratories (MBLs) in Croatia. Statements were designed to address preanalytical, analytical and postanalytical procedures of cerebrospinal, pleural, peritoneal (ascites), pericardial, seminal, synovial, amniotic fluid and sweat. Participants were asked to declare the strength of agreement with proposed statements using a Likert scale. Mean scores for corresponding separate statements divided according to health care setting were calculated and compared.
\end{abstract}

Results: The survey response rate was 0.64 (58 / 90). None of the participating private MBLs declared to analyse EBF. We report a mean score of 3.45 obtained for all statements evaluated. Deviations from desirable procedures were demonstrated in all EBF testing phases. Minor differences in procedures used for EBF analysis comparing secondary and tertiary health care MBLs were found. The lowest scores were obtained for statements regarding quality control procedures in EBF analysis, participation in proficiency testing programmes and provision of interpretative comments on EBF's test reports.

Conclusions: Although good laboratory EBF practice is present in Croatia, procedures for EBF analysis should be further harmonized to improve the quality of EBF testing and patient safety.

Key words: extravascular body fluids; cerebrospinal fluid; serous fluids; survey; harmonization

\section{Introduction}

Whole blood, serum, plasma and urine are considered standard samples submitted for analysis in routine laboratory practice. However, occasionally, clinical laboratories are requested to perform analyses on a variety of extravascular body fluids (EBF) $(1,2)$. EBF have multiple roles: they function as ana- tomical barriers lubricating the surfaces of lining membranes and maintain the homeostasis of organ systems surrounding them. The accumulation and/or change in EBF's composition occur in various pathological conditions comprising systemic and localized disorders (3). For the purpose of this 
investigation, the term EBF will apply to cerebrospinal fluid (CSF), serous fluids (pleural, peritoneal (ascites) and pericardial), synovial fluid, amniotic fluid, seminal fluid and sweat (3).

Laboratory testing of EBF involves a wide spectrum of analyses with varying clinical utilities. Although considered an important part of disease diagnosis and management, it is challenging for several reasons including the EBF's matrix effect, lack of commercial assays validated for assessing effusions and absence of established reference ranges available for EBF testing (3-5).

Several documents issued by the Clinical and Laboratory Standards Institute (CLSI) are of great importance in guiding laboratory professionals through EBF laboratory testing (3,6-8), but these documents do not address the analysis of each specific EBF in the same comprehensive manner. Furthermore, national recommendations addressing EBF clinical laboratory testing are not available in Croatia. However, in 2007, the Croatian Chamber of Medical Biochemists (CCMB) issued a document comprising a list of recommended methods for CSF, synovial, amniotic, seminal, pleural, peritoneal fluid and sweat analysis with corresponding reference ranges and/or clinical decision limits (9). Although in need of revision, this document should be considered as benchmark for future national harmonization efforts in this field.

Harmonization of EBF laboratory testing could undoubtedly contribute to quality improvement of laboratory services and enhance patient safety (10). Currently used procedures in EBF analysis in Croatian Medical Biochemistry Laboratories (MBLs) are largely unknown. Since the first step towards harmonization of EBF laboratory testing comprises the identification and understanding of differences among practices, our aim was to investigate preanalytical, analytical and postanalytical procedures used in EBF laboratory testing in Croatian MBLs. We hypothesized that existing procedures are not harmonized and tried to identify key aspects that should be addressed in future harmonization attempts in this field.

\section{Materials and methods}

\section{Questionnaire}

MBL's pertaining to secondary (special and general hospitals), tertiary (clinics, clinical hospitals and clinical hospital centres) and private health care institutions (MBLs that bill the patient for laboratory services provided) were surveyed. These MBLs have the authority and competency to perform EBF analyses in Croatia. A total of 90 MBL's were identified using the Croatian Society of Medical Biochemistry and Laboratory Medicine (CSMBLM) database. MBL's managers were invited (by e-mail) to participate in an online survey created using the survey platform SurveyMonkey (SurveyMonkey Inc., Palo Alto, USA). Due to poor response rate in the first round (May 2015), members of the Working group for extravascular body fluids (WG EBF) contacted by phone each laboratory manager who failed to participate in the first round, briefly explaining the aim of the questionnaire and asking to participate in the survey. Following consent, the link for the online survey was mailed to them once again. Anonymity was ensured to all survey participants.

The WG EBF questionnaire exploring practices used in laboratory testing of EBF was divided in nine sections. The first section included questions on laboratory type (i.e. health care setting) and confirmation of performing EBF laboratory testing. MBLs were asked to estimate the average number of EBF analysed per year and to identify personnel involved in EBF analysis. Furthermore, this section included four questions regarding the test request form and type of containers used for EBF transport to the laboratory.

The remaining eight sections of the survey were designed to address the analysis of specific EBF: CSF, serous fluids, seminal, synovial, amniotic fluid and sweat. Specific EBF sections comprised statements describing selected procedures regarding preanalytical, analytical and postanalytical phase of EBF analysis. The participants were asked to declare the strength of agreement (i.e. the agreement of EBF analysis procedures performed in their laboratories) with each proposed statement 
in the survey, according to a Likert scale graded as 1 (never), 2 (rarely), 3 (sometimes), 4 (often) and 5 (always). The most favourable responses are represented with the highest score.

\section{Statistical analysis}

Qualitative data were presented as counts and proportions $(\mathrm{N}<100)$. The number of EBF analyses performed yearly was presented as median and interquartile range (IQR). Data obtained from the Likert scale used in our survey was transformed into grades from 1 to 5 (corresponding to grades in the Croatian educational system) for comparison purposes. Consequently, agreement with individual statements was presented as mean score. The mean score was calculated for the total group of MBLs and for MBLs divided according to health care setting (secondary and tertiary health care). Differences between qualitative data were tested using the Fisher's exact test $(\mathrm{N}<30)$. Differences in mean scores for MBLs divided according to health care setting were tested using the Mann-Whitney test for independent samples $(\mathrm{N}<30)$. The level of significance was set at $P<0.05$. Statistical analysis was performed using MedCalc, (v 11.5.1, Ostend, Belgium).

\section{Results}

Fifty-eight MBLs pertaining to secondary and tertiary health care facilities and private laboratories participated in the survey. The survey response rate was 0.64 (58 / 90). Fourteen MBLs were excluded from further analysis because of missing general characteristics (i.e. respondents failed to declare the type of MBL needed for further analysis) and/or did not respond to any question of the survey, in spite of acknowledging the performance of EBF analysis. Hence, a total of 44 (0.49) surveyed private, secondary and tertiary health care Croatian laboratories were included in the analysis.

The distribution of participating MBLs according to health care setting is presented in Table 1. None of the participating private MBL declared to analyse EBF. The majority (24 / 29) of the secondary and tertiary care MBLs which declared to analyse
TABLE 1. Distribution of surveyed MBLs by health care setting

\begin{tabular}{lcc}
\hline \multicolumn{1}{c}{ Category } & $\begin{array}{c}\text { MBLs by health } \\
\text { care setting, } \mathbf{N}=\mathbf{4 4}\end{array}$ & $\begin{array}{c}\text { MBLs performing } \\
\text { EBF analysis, } \mathbf{N}=\mathbf{2 9}\end{array}$ \\
\hline $\begin{array}{l}\text { Private, N } \\
\text { (proportion) }\end{array}$ & $7(0.16)$ & $0(0)$ \\
$\begin{array}{l}\text { Secondary, N } \\
\text { (proportion) }\end{array}$ & $26(0.59)$ & $20(0.69)$ \\
$\begin{array}{l}\text { Tertiary, N } \\
\text { (proportion) }\end{array}$ & $11(0.25)$ & $9(0.31)$ \\
\hline
\end{tabular}

MBLs - medical biochemistry laboratories; EBF - extravascular body fluid. Secondary health care MBLs comprise laboratories located in special and general hospitals. Tertiary health care MBLs comprise laboratories located in clinics, clinical hospitals and clinical hospital centres. Private laboratories bill the customer for laboratory services provided.

EBF stated that all laboratory personnel (i.e. managing personnel - Master of medical biochemistry and Specialists in laboratory medicine, and nonmanaging personnel - Bachelor of science in laboratory diagnostics and Medical laboratory technicians) is involved in EBF laboratory testing (data not shown). Furthermore, the number EBF analyzed yearly in surveyed MBLs is presented in Table 2. Data on EBF requesting, sampling and transporting are presented in Table 3.

TABLE 2. Estimated frequency of EBF analysis performed yearly in surveyed MBLs

\begin{tabular}{lcc}
\hline \multicolumn{1}{c}{ Type of EBF } & $\begin{array}{c}\text { MBLs performing } \\
\text { EBF analysis, } \\
\text { N = 29 }\end{array}$ & $\begin{array}{c}\text { EBF analyzed } \\
\text { yearly, } \\
\text { N (median, IQR) }\end{array}$ \\
\hline $\begin{array}{l}\text { CSF, N (proportion) } \\
\text { Pleural effusion, N } \\
\text { (proportion) }\end{array}$ & $26(0.90)$ & $100(15-219)$ \\
$\begin{array}{l}\text { Seminal fluid, N } \\
\text { (proportion) }\end{array}$ & $8(0.28)$ & $131(50-400)$ \\
$\begin{array}{l}\text { Sweat, N } \\
\text { (proportion) }\end{array}$ & $10(0.34)$ & $50(14-288)$ \\
$\begin{array}{l}\text { Amniotic fluid, N } \\
\text { (proportion) }\end{array}$ & $3(0.10)$ & $10(10-20)$ \\
$\begin{array}{l}\text { Synovial fluid, N } \\
\text { (proportion) }\end{array}$ & $5(0.17)$ & $5(2-13)$ \\
\hline
\end{tabular}

MBLs - medical biochemistry laboratories; EBF - extravascular body fluid; CSF - cerebrospinal fluid; IQR - interquartile range. 
TABLE 3. EBF's test request and container used for EBF transport

\begin{tabular}{|c|c|c|c|c|}
\hline \multirow[b]{2}{*}{ Question } & \multicolumn{3}{|c|}{ Affirmative answers of MBLs by health care setting, $N$ (proportion) } & \multirow[b]{2}{*}{$\mathbf{P}$} \\
\hline & $\begin{array}{l}\text { All MBLs, } \\
N=29\end{array}$ & $\begin{array}{l}\text { Secondary health care } \\
\text { MBLs, } \\
\text { N }=\mathbf{2 0}\end{array}$ & $\begin{array}{l}\text { Tertiary health care } \\
\text { MBLs, } \\
\text { N=9 }\end{array}$ & \\
\hline $\begin{array}{l}\text { Are all the necessary data (comprising the } \\
\text { patients' name, date of birth, department, } \\
\text { physicians' name, sample type, ordered test) } \\
\text { clearly stated on the test request? }\end{array}$ & $28(0.97)$ & $19(0.95)$ & $9(1.00)$ & 1.000 \\
\hline $\begin{array}{l}\text { Is the patient's primary diagnosis clearly } \\
\text { stated on the test request? }\end{array}$ & $19(0.66)$ & $13(0.65)$ & $6(0.67)$ & 1.000 \\
\hline $\begin{array}{l}\text { Is the sampling time available on the test } \\
\text { request? }\end{array}$ & $17(0.59)$ & $12(0.60)$ & $5(0.56)$ & 1.000 \\
\hline $\begin{array}{l}\text { Are EBF samples delivered to the laboratory } \\
\text { exclusively in clean, additive-free } \\
\text { containers? }\end{array}$ & $22(0.76)$ & $17(0.85)$ & $5(0.56)$ & 0.158 \\
\hline \multicolumn{5}{|c|}{$\begin{array}{l}\text { MBLs - medical biochemistry laboratories; EBF - extravascular body fluid. Secondary health care MBLs comprise laboratories } \\
\text { located in special and general hospitals. Tertiary health care MBLs comprise laboratories located in clinics, clinical hospitals and } \\
\text { clinical hospital centres. } \\
\text { Differences between secondary and tertiary health care MBLs were calculated using the Fisher's exact test. P<0.05 was considered } \\
\text { statistically significant. }\end{array}$} \\
\hline
\end{tabular}

\section{Cerebrospinal fluid}

Mean scores for laboratory procedures used in CSF analysis obtained from participating MBLs performing CSF analysis are presented in Table 4. The lowest mean scores were obtained for statements addressing CSF sample delivery, the calculation of albumin and immunoglobulin quotients $\left(Q_{\text {Alb }}\right.$ and $\mathrm{Q}_{\mathrm{Ig}}$ ) and quality control (QC) procedures instituted for CSF analyses. According to the high mean score obtained, the STAT panel for CSF analysis generally comprises total cell count with morphological analysis and total protein, glucose, lactate, chloride and C-reactive protein (CRP), with differences observed in practices between secondary and tertiary health care MBLs $(P=0.025)$. Total CSF cell count is determined manually in the majority of the surveyed MBLs. The CSF cell count is reported in SI units, with differences observed in practices between secondary and tertiary health care MBLs $(P=0.039)$. Similarly, the majority of the participating MBLs declared to measure the CSF's total protein concentration using a pyrogallol red method. Participating MBLs often record the delivery time of CSF samples to the laboratory (mean score 4.38). Additionally, they declared that STAT CSF analyses are available to the responsible clinician in one hour. In general, the type of puncture/sample type is often specified on the CSF test request. A mean score of 3.38 for all laboratory procedures used in CSF analysis was obtained.

\section{Serous fluids}

Table 5 presents mean scores for procedures used in serous fluid analysis, obtained from MBLs which declared to perform pleural, peritoneal and pericardial fluid analysis. Concomitant serum samples are (only) sometimes delivered with serous fluid samples to the laboratory. The majority of MBLs declared written procedures for serous fluid laboratory analysis are available to laboratory staff. Overall, laboratory testing of pleural fluid in Croatian MBLs comprises fluid's gross examination followed by total protein (TP) and lactate dehydrogenase (LD) analysis in both pleural fluid and serum sample, as evidenced by the mean total scores obtained. In addition, peritoneal and pericardial fluid evaluation comprises albumin analysis. The CCMB decision limits for pleural and peritoneal fluid are 
TABLE 4. Distribution of survey responses and comparison of mean scores for procedures used in CSF analysis

\begin{tabular}{|c|c|c|c|c|c|c|c|c|c|c|}
\hline \multirow[b]{2}{*}{ Statement } & \multirow{2}{*}{ 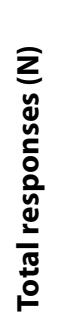 } & \multicolumn{5}{|c|}{ Survey responses (N, proportion) } & \multicolumn{3}{|c|}{$\begin{array}{l}\text { Score according to } \\
\text { health care setting, } \\
\text { mean value }\end{array}$} & \multirow[b]{2}{*}{$\mathbf{P}$} \\
\hline & & 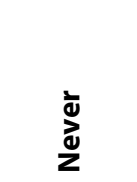 & $\frac{\lambda}{\frac{\lambda}{d}}$ & 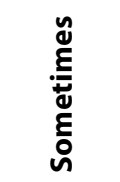 & 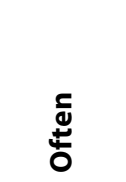 & $\underset{\substack{\frac{\pi}{3} \\
\frac{3}{4}}}{n}$ & $\frac{\overline{0}}{\overline{0}}$ & 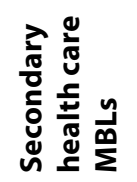 & 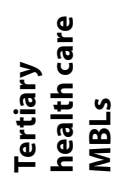 & \\
\hline $\begin{array}{l}\text { 1. The CSF is delivered to the laboratory } \\
\text { in three different, clearly identified } \\
\text { containers. }\end{array}$ & 26 & $15(0.58)$ & $1(0.04)$ & $3(0.12)$ & $4(0.15)$ & $3(0.12)$ & 2.19 & 2.59 & 1.44 & 0.083 \\
\hline $\begin{array}{l}\text { 2. The type of puncture/sample is } \\
\text { specified in the test request form. }\end{array}$ & 26 & $4(0.15)$ & $2(0.08)$ & $1(0.04)$ & $1(0.04)$ & $18(0.69)$ & 4.04 & 3.76 & 4.56 & 0.182 \\
\hline $\begin{array}{l}\text { 3. The delivery time of the sample to the } \\
\text { laboratory is recorded. }\end{array}$ & 26 & $3(0.11)$ & $0(0)$ & $1(0.04)$ & $2(0.08)$ & $20(0.77)$ & 4.38 & 4.59 & 4.00 & 0.370 \\
\hline $\begin{array}{l}\text { 4. The STAT panel in CSF testing } \\
\text { comprises the determination of total } \\
\text { cell count, morphological analysis of } \\
\text { cells, and determination of total protein, } \\
\text { glucose, lactate, chloride and CRP } \\
\text { concentrations. }\end{array}$ & 26 & $4(0.16)$ & $0(0)$ & $0(0)$ & $3(0.12)$ & $19(0.73)$ & 4.27 & 4.71 & 3.44 & 0.025 \\
\hline $\begin{array}{l}\text { 5. Total CSF cell count is determined by } \\
\text { counting the cells in the native sample } \\
\text { using the Fuchs-Rosenthal's chamber. }\end{array}$ & 26 & $2(0.08)$ & $0(0)$ & $1(0.04)$ & $1(0.04)$ & $22(0.85)$ & 4.58 & 4.71 & 4.33 & 0.506 \\
\hline $\begin{array}{l}\text { 6. The total CSF cell count is determined } \\
\text { using the EBF mode on the automated } \\
\text { haematology analyser. }\end{array}$ & 25 & $16(0.64)$ & $2(0.08)$ & $0(0)$ & $2(0.08)$ & $5(0.20)$ & 2.12 & 2.00 & 2.33 & 0.586 \\
\hline $\begin{array}{l}\text { 7. The total CSF cell count is reported as } \\
\text { number of cells } \times 10^{6} / \mathrm{L} \text {. }\end{array}$ & 24 & $2(0.08)$ & $0(0)$ & $0(0)$ & $1(0.04)$ & $21(0.88)$ & 4.63 & 5.00 & 4.00 & 0.039 \\
\hline $\begin{array}{l}\text { 8. The results of STAT analyses in CSF } \\
\text { testing are available to clinicians within } \\
60 \text { minutes upon sample receipt. }\end{array}$ & 25 & $1(0.04)$ & $0(0)$ & $0(0)$ & $4(0.16)$ & $20(0.80)$ & 4.68 & 4.81 & 4.44 & 0.762 \\
\hline $\begin{array}{l}\text { 9. Total proteins in CSF samples are } \\
\text { determined using the pyrogallol red } \\
\text { method. }\end{array}$ & 26 & $6(0.23)$ & $0(0)$ & $0(0)$ & $0(0)$ & $20(0.77)$ & 4.08 & 4.06 & 4.11 & 0.945 \\
\hline $\begin{array}{l}\text { 10. When calculating the } Q_{A l b} \text { and } Q_{\mid g} \text { the } \\
\text { same calibration curve is used for serum } \\
\text { and CSF parameters. }\end{array}$ & 20 & $15(0.75)$ & $0(0)$ & $0(0)$ & $0(0)$ & $5(0.25)$ & 2.00 & 1.33 & 3.00 & 0.056 \\
\hline $\begin{array}{l}\text { 11. The laboratory has established an } \\
\text { internal quality control scheme for total } \\
\text { CSF cell count. }\end{array}$ & 24 & $14(0.58)$ & $1(0.04)$ & $4(0.17)$ & $2(0.08)$ & $3(0.13)$ & 2.13 & 2.27 & 1.89 & 0.536 \\
\hline $\begin{array}{l}\text { 12. The laboratory participates in external } \\
\text { proficiency testing programmes for CSF } \\
\text { chemistries. }\end{array}$ & 24 & $21(0.88)$ & $0(0)$ & $0(0)$ & $0(0)$ & $3(0.13)$ & 1.50 & 1.27 & 1.89 & 0.335 \\
\hline
\end{tabular}

MBLs - medical biochemistry laboratories; CSF - cerebrospinal fluid; EBF - extravascular body fluid; CRP - C-reactive protein; STAT analyses - emergency analyses.

Secondary health care MBLs comprise laboratories located in special and general hospitals. Tertiary health care MBLs comprise laboratories located in clinics, clinical hospitals and clinical hospital centres.

$\mathrm{Q}_{\mathrm{Alb}}$ and $\mathrm{Q}_{\mathrm{Ig}}$ - albumin and immunoglobulin quotients.

Differences between secondary and tertiary health care MBLs were calculated using the Mann-Whitney test for independent samples. $\mathrm{P}<0.05$ was considered statistically significant. 
TABLE 5. Distribution of survey responses and comparison of mean scores for procedures used in serous fluid analysis

\begin{tabular}{|c|c|c|c|c|c|c|c|c|c|c|}
\hline \multirow[b]{2}{*}{ Statement } & \multirow{2}{*}{ 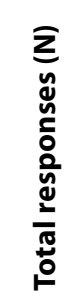 } & \multicolumn{5}{|c|}{ Survey responses (N, proportion) } & \multicolumn{3}{|c|}{$\begin{array}{l}\text { Score according to health } \\
\text { care setting, mean value }\end{array}$} & \multirow[b]{2}{*}{$\mathbf{P}$} \\
\hline & & ¿े & 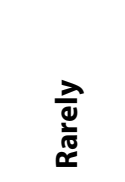 & 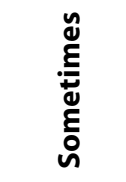 & $\stackrel{c}{巳}$ & $\frac{\sum^{n}}{\frac{\pi}{\alpha}}$ & $\begin{array}{l}\overline{\overline{0}} \\
\overline{0} \\
\overline{0}\end{array}$ & 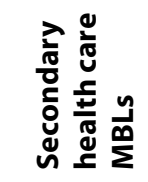 & 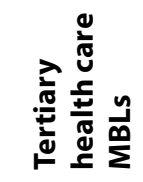 & \\
\hline \multicolumn{11}{|c|}{ A) PLEURAL FLUID } \\
\hline $\begin{array}{l}\text { 1. Serum samples are always delivered } \\
\text { to the laboratory in parallel with the } \\
\text { pleural fluid sample. }\end{array}$ & 25 & $2(0.08)$ & $4(0.16)$ & $9(0.36)$ & $5(0.20)$ & $5(0.20)$ & 3.28 & 3.24 & 3.38 & 0.905 \\
\hline $\begin{array}{l}\text { 2. Written procedures for preparation } \\
\text { and analysis of pleural fluid samples } \\
\text { are available to laboratory staff. }\end{array}$ & 24 & $4(0.17)$ & $1(0.04)$ & $0(0)$ & $2(0.08)$ & $17(0.71)$ & 4.13 & 4.38 & 4.63 & 0.465 \\
\hline $\begin{array}{l}\text { 3. Pleural fluid analysis includes } \\
\text { recording its appearance. }\end{array}$ & 25 & $5(0.20)$ & $0(0)$ & $1(0.04)$ & $1(0.04)$ & $18(0.72)$ & 4.08 & 4.35 & 3.50 & 0.378 \\
\hline $\begin{array}{l}\text { 4. The analysis of pleural fluid } \\
\text { comprises the determination of } \\
\text { protein and LD in serum and fluid } \\
\text { sample. }\end{array}$ & 25 & $3(0.12)$ & $1(0.04)$ & $1(0.04)$ & $5(0.20)$ & $15(0.60)$ & 4.12 & 4.35 & 3.63 & 0.335 \\
\hline $\begin{array}{l}\text { 5. The laboratory has established } \\
\text { an internal quality control scheme } \\
\text { specific for analytes in pleural fluid. }\end{array}$ & 24 & $5(0.21)$ & $0(0)$ & $0(0)$ & $1(0.04)$ & $18(0.75)$ & 4.13 & 4.24 & 3.86 & 0.751 \\
\hline $\begin{array}{l}\text { 6. The test report contains decision } \\
\text { limits for pleural fluid analytes } \\
\text { recommended by the CCMB. }\end{array}$ & 24 & $9(0.38)$ & $0(0)$ & $0(0)$ & $1(0.04)$ & $14(0.58)$ & 3.46 & 3.53 & 3.29 & 0.860 \\
\hline $\begin{array}{l}\text { 7. Apart from pleural fluid analysis test } \\
\text { results, the test report also contains } \\
\text { the interpretation of the results } \\
\text { obtained (interpretative comment). }\end{array}$ & 24 & $\begin{array}{l}13 \\
(0.54)\end{array}$ & $4(0.17)$ & $4(0.17)$ & $1(0.04)$ & $2(0.08)$ & 1.96 & 2.24 & 1.29 & 0.144 \\
\hline \multicolumn{11}{|c|}{ B) PERITONEAL FLUID } \\
\hline $\begin{array}{l}\text { 1. Serum samples are always delivered } \\
\text { to the laboratory in parallel with the } \\
\text { peritoneal fluid sample. }\end{array}$ & 16 & $2(0.13)$ & $2(0.13)$ & $5(0.31)$ & $4(0.25)$ & $3(0.19)$ & 3.25 & 3.08 & 3.75 & 0.425 \\
\hline $\begin{array}{l}\text { 2. Peritoneal fluid analysis includes } \\
\text { recording its appearance. }\end{array}$ & 16 & $3(0.19)$ & $0(0)$ & $1(0.06)$ & $2(0.13)$ & $10(0.63)$ & 4.00 & 4.00 & 4.00 & 0.738 \\
\hline $\begin{array}{l}\text { 3. Peritoneal fluid analysis comprises } \\
\text { the determination of total protein, LD } \\
\text { and albumin concentrations in serum } \\
\text { and fluid sample. }\end{array}$ & 16 & $0(0)$ & $1(0.06)$ & $1(0.06)$ & $4(0.25)$ & $10(0.63)$ & 4.44 & 4.50 & 4.25 & 0.546 \\
\hline $\begin{array}{l}\text { 4. Peritoneal fluid analysis comprises } \\
\text { the calculation of ascites/serum protein } \\
\text { ratio and ascites/serum LD ratio. }\end{array}$ & 16 & $\begin{array}{l}10 \\
(0.63)\end{array}$ & $1(0.06)$ & $2(0.13)$ & $1(0.06)$ & $2(0.13)$ & 2.00 & 1.75 & 2.75 & 0.385 \\
\hline $\begin{array}{l}\text { 5. Methods applied in peritoneal } \\
\text { fluid analysis are verified for their } \\
\text { intended use against manufacturer's } \\
\text { performance claims. }\end{array}$ & 15 & $2(0.13)$ & $0(0)$ & $1(0.07)$ & $1(0.07)$ & $11(0.73)$ & 4.27 & 4.00 & 5.00 & 0.214 \\
\hline $\begin{array}{l}\text { 6. Written procedures for preparation } \\
\text { and analysis of peritoneal fluid } \\
\text { samples are available to laboratory } \\
\text { staff. }\end{array}$ & 15 & $3(0.20)$ & $0(0)$ & $0(0)$ & $0(0)$ & $12(0.80)$ & 4.20 & 4.64 & 3.00 & 0.131 \\
\hline
\end{tabular}




\begin{tabular}{|c|c|c|c|c|c|c|c|c|c|c|}
\hline $\begin{array}{l}\text { 7. The test report contains decision } \\
\text { limits for peritoneal fluid analytes } \\
\text { recommended by the CCMB. }\end{array}$ & 16 & $5(0.31)$ & $1(0.06)$ & $0(0)$ & $0(0)$ & $10(0.63)$ & 3.56 & 3.42 & 4.00 & 0.637 \\
\hline $\begin{array}{l}\text { 8. Apart from peritoneal fluid } \\
\text { analysis test results, the test report } \\
\text { also contains the interpretation of } \\
\text { the results obtained (interpretative } \\
\text { comment). }\end{array}$ & 16 & $\begin{array}{l}10 \\
(0.63)\end{array}$ & $1(0.06)$ & $2(0.13)$ & $0(0)$ & $3(0.19)$ & 2.06 & 2.42 & 1.00 & 0.109 \\
\hline
\end{tabular}
comment).

\section{C) PERICARDIAL FLUID}

\begin{tabular}{|c|c|c|c|c|c|c|c|c|c|c|}
\hline $\begin{array}{l}\text { 1. Serum samples are always delivered } \\
\text { to the laboratory in parallel with the } \\
\text { pericardial fluid sample. }\end{array}$ & 7 & $0(0)$ & $1(0.14)$ & $2(0.29)$ & $1(0.14)$ & $3(0.43)$ & 3.86 & 3.60 & 4.50 & 0.434 \\
\hline $\begin{array}{l}\text { 2. Written procedures for preparation } \\
\text { and analysis of pericardial fluid } \\
\text { samples are available to laboratory } \\
\text { staff. }\end{array}$ & 7 & $0(0)$ & $0(0)$ & $0(0)$ & $0(0)$ & $7(1.00)$ & 5.00 & 5.00 & 5.00 & 1.000 \\
\hline $\begin{array}{l}\text { 3. Pericardial fluid analysis comprises } \\
\text { the determination of total protein, LD } \\
\text { and albumin concentrations in serum } \\
\text { and fluid sample. }\end{array}$ & 7 & $0(0)$ & $0(0)$ & $0(0)$ & $2(0.29)$ & $5(0.71)$ & 4.71 & 4.80 & 4.50 & 0.522 \\
\hline $\begin{array}{l}\text { 4. Apart from pericardial fluid } \\
\text { analysis test results, the test report } \\
\text { also contains the interpretation of } \\
\text { the results obtained (interpretative } \\
\text { comment). }\end{array}$ & 7 & $5(0.71)$ & $0(0)$ & $0(0)$ & $0(0)$ & $2(0.29)$ & 2.14 & 2.60 & 1.00 & 0.393 \\
\hline
\end{tabular}

MBLs - medical biochemistry laboratories; LD - lactate dehydrogenase; CCMB - Croatian Chamber of Medical Biochemistry. Secondary health care MBLs comprise laboratories located in special and general hospitals. Tertiary health care MBLs comprise laboratories located in clinics, clinical hospitals and clinical hospital centres.

Differences between secondary and tertiary health care MBLs were calculated using the Mann-Whitney test for independent samples. $\mathrm{P}<0.05$ was considered statistically significant.

listed on the majority of test reports. In general, similar favourable scores were obtained for procedures used in peritoneal fluid analysis of surveyed MBLs, except for the statement regarding the calculation of ascites / serum protein and ascites / serum LD ratio (mean score 1.75). Furthermore, high mean total score was obtained for the statement regarding the verification of performance claims for methods used in peritoneal fluid analysis (mean score 4.00). Favourable high mean total scores were obtained for all the statements regarding pericardial fluid analysis, except for the inclusion of an interpretative comment on the pericardial fluid test report. Indeed, all the surveyed MBLs rarely include interpretative comments on serous fluid test reports for pleural, peritoneal and pericardial fluid, respectively. A score of 3.61 for laboratory procedures used in serous fluids analysis was obtained. The comparison of scores ob- tained for MBLs performing serous fluid analysis divided according health care setting revealed no difference in procedures used.

\section{Seminal fluid}

Mean total scores for procedures used in seminal fluid analysis of surveyed MBLs are presented in Table 6. MBLs performing seminal fluid analysis have written instructions for patient preparation and written procedures for sample analysis available to laboratory personnel (mean scores 4.86 and 5.00 , respectively). Seminal fluid analysis results are usually used in assisted reproductive technology procedures. Considering that seminal fluid sampling is usually located outside the laboratory, majority of MBLs performing seminal fluid analysis implemented procedures for the adequate delivery of seminal fluid sample to the laboratory. Seminal fluid analysis in general comprises evaluation 
TABLE 6. Distribution of survey responses and comparison of mean scores for procedures used in seminal fluid analysis

\begin{tabular}{|c|c|c|c|c|c|c|c|c|c|}
\hline \multirow[b]{2}{*}{ Statement } & \multicolumn{5}{|c|}{ Survey responses $(\mathrm{N}=\mathbf{8}), \mathrm{N}$ (proportion) } & \multicolumn{3}{|c|}{$\begin{array}{l}\text { Score according to health } \\
\text { care setting, mean value }\end{array}$} & \multirow[b]{2}{*}{$\mathbf{P}$} \\
\hline & 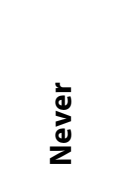 & 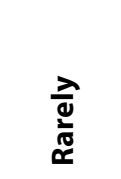 & 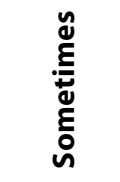 & $\stackrel{c}{\Phi}$ & 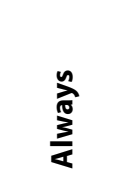 & $\overline{\overline{0}}$ & 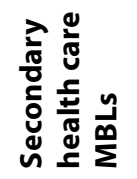 & 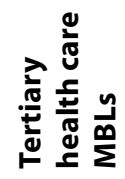 & \\
\hline $\begin{array}{l}\text { 1. Written instructions on how to prepare } \\
\text { for seminal fluid analysis are available to } \\
\text { patients. }\end{array}$ & $1(0.13)$ & $0(0)$ & $0(0)$ & $0(0)$ & $7(0.88)$ & 4.86 & 4.83 & 5.00 & 0.663 \\
\hline $\begin{array}{l}2 \text { Written procedures for preparation and } \\
\text { analysis of seminal fluid samples are available } \\
\text { to laboratory staff. }\end{array}$ & $0(0)$ & $0(0)$ & $0(0)$ & $0(0)$ & $8(1.00)$ & 5.00 & 5.00 & 5.00 & 1.000 \\
\hline $\begin{array}{l}\text { 3. Seminal fluid analysis results are used in } \\
\text { ART procedures. }\end{array}$ & $0(0)$ & $1(0.13)$ & $4(0.50)$ & $2(0.25)$ & $1(0.13)$ & 3.38 & 3.33 & 3.50 & 0.733 \\
\hline $\begin{array}{l}\text { 4. Seminal fluid sampling takes place in a } \\
\text { room near the laboratory. }\end{array}$ & $4(0.50)$ & $1(0.13)$ & $0(0)$ & $2(0.25)$ & $1(0.13)$ & 2.38 & 2.17 & 3.00 & 0.608 \\
\hline $\begin{array}{l}\text { 5. Procedures for adequate/proper semen } \\
\text { sample delivery to the laboratory are } \\
\text { instituted. }\end{array}$ & $0(0)$ & $0(0)$ & $1(0.13)$ & $4(0.50)$ & $3(0.37)$ & 4.25 & 4.17 & 4.50 & 0.606 \\
\hline $\begin{array}{l}\text { 6. Seminal fluid analysis comprises } \\
\text { determination of fluid appearance, fluid } \\
\text { volume, liquefaction time, viscosity and } \mathrm{pH} \text {. }\end{array}$ & $1(0.13)$ & $0(0)$ & $1(0.13)$ & $2(0.25)$ & $4(0.50)$ & 4.00 & 4.50 & 2.50 & 0.124 \\
\hline $\begin{array}{l}\text { 7. Seminal fluid analysis comprises the } \\
\text { analysis of native semen, sperm analysis, } \\
\text { sperm vitality analysis, sperm concentration, } \\
\text { determination of other cells in semen and } \\
\text { sperm morphology. }\end{array}$ & $0(0)$ & $0(0)$ & $0(0)$ & $2(0.25)$ & $6(0.75)$ & 4.75 & 4.83 & 4.50 & 0.445 \\
\hline $\begin{array}{l}\text { 8. The patient's therapy is listed on the test } \\
\text { request. }\end{array}$ & $4(0.50)$ & $3(0.38)$ & $1(0.13)$ & $0(0)$ & $0(0)$ & 1.63 & 1.83 & 1.00 & 0.169 \\
\hline $\begin{array}{l}\text { 9. If very low sperm number is found in } \\
\text { seminal sample, the sampling error ( } \% \mathrm{SE}) \text { is } \\
\text { reported on the test report. }\end{array}$ & $3(0.37)$ & $4(0.50)$ & $0(0)$ & $1(0.13)$ & $0(0)$ & 1.88 & 2.17 & 1.00 & 0.086 \\
\hline $\begin{array}{l}\text { 10. The test report contains the referent } \\
\text { ranges for seminal fluid analytes } \\
\text { recommended by the CCMB. }\end{array}$ & $0(0)$ & $1(0.13)$ & $0(0)$ & $3(0.33)$ & $4(0.50)$ & 4.25 & 4.17 & 4.50 & 0.864 \\
\hline $\begin{array}{l}\text { 11. The test report also contains the } \\
\text { interpretation of the results obtained } \\
\text { (interpretative comment). }\end{array}$ & $4(0.50)$ & $3(0.38)$ & $0(0)$ & $1(0.13)$ & $0(0)$ & 1.75 & 2.00 & 1.00 & 0.169 \\
\hline $\begin{array}{l}\text { 12. The laboratory has established an internal } \\
\text { quality control scheme specific for analytes } \\
\text { determined in seminal fluid. }\end{array}$ & $4(0.50)$ & $0(0)$ & $2(0.25)$ & $2(0.25)$ & $0(0)$ & 2.25 & 2.17 & 2.50 & 0.733 \\
\hline $\begin{array}{l}\text { 13. The laboratory participates in external } \\
\text { quality assessment programmes for seminal } \\
\text { fluid chemistries. }\end{array}$ & $7(0.87)$ & $0(0)$ & $1(0.13)$ & $0(0)$ & $0(0)$ & 1.25 & 1.33 & 1.00 & 0.663 \\
\hline
\end{tabular}

MBLs - medical biochemistry laboratories; ART - assisted reproductive technology; CCMB - Croatian Chamber of Medical Biochemistry.

Secondary health care MBLs comprise laboratories located in special and general hospitals. Tertiary health care MBLs comprise laboratories located in clinics, clinical hospitals and clinical hospital centres.

Differences between secondary and tertiary health care MBLs were calculated using the Mann-Whitney test for independent samples. $\mathrm{P}<0.05$ was considered statistically significant. 
of fluid appearance, volume, liquefaction time, viscosity and $\mathrm{pH}$, sperm vitality analysis, sperm concentration, determination of other cells in semen and sperm morphology. Unfavourable total scores were obtained for statements regarding the listing of the patient's therapy on the test request, the inclusion of interpretative comments on test report and the implementation of internal and external seminal fluid quality control procedures (mean scores 1.63, 1.75, 2.25 and 1.25, respectively). An overall score of 3.37 for laboratory procedures used in seminal fluid analysis was obtained. No difference in procedures used in seminal fluid analysis was found comparing secondary and tertiary care MBLs.

\section{Other EBFs}

The survey section addressing sweat analysis consisted of 10 statements covering all three phases of sweat laboratory testing (including statements investigating methods used, availability of written instructions, demographics and analytical details, quality control and external quality assessment, and reference ranges used. Unfortunately, only 3 (out of 44) responding MBLs filled out the questionnaire on sweat testing. Similar questions were introduced in sections covering synovial fluid (6 questions) and amniotic fluid analysis (10 questions). Only three and two participating MBLs filled out the section covering synovial and amniotic fluid, respectively. Considering this small sample, the statistical analysis for the aforementioned EBF was not performed and data on individual statements are not presented.

\section{Discussion}

This survey was designed to better understand procedures currently used in EBF analysis in Croatia. We were unable to find any similar national and international investigation. A mean score of 3.45 (on a scale from 1 to 5) for all statements can be considered an indicator of good laboratory EBF practice. Individually, procedures used in serous fluids analysis scored 3.61, while procedures for CSF and seminal fluid analysis scored 3.38 and 3.37, respectively. Hence, EBF analysis in Croatia could be improved and better harmonized, in all the testing phases of EBF analysis. Overall, the least favourable responses (evidenced by the lowest scores) were obtained for statements regarding quality control procedures used for EBF analyses, participation in proficiency testing programmes for EBF and provision of interpretative comments on EBF's test reports. These results reflect the lack of commercially available commutable EBF control materials and the lack of awareness of interpretative comments as key components of clinical counselling and patient management (11).

We demonstrated that EBF analysis in Croatia is performed in secondary and/or tertiary health care MBLs, as was to be expected given the complexity of health care provided in these institutions. According to the survey results, the most frequently analysed EBF yearly in Croatian MBLs are seminal fluid, CSF and pleural effusions. Request forms for EBF analysis include extensive patient identification data along with the ordering physicians' name, EBF type, test ordered and sampling time, meeting regulatory requirements for pre-examination processes $(7,12,13)$. We also report that EBF are usually delivered to the laboratory in clean, additive free containers, which reduces the risk of preanalytical error due to inadequate additive choice and/or contamination.

The sequential collection of CSF into 3 clearly labelled containers is recommended. The first tube should be used for chemistry and/or immunology testing; the second is intended for microbiology and the third/fourth for cellular analysis/cytology $(7,14,15)$. According to our results, CSF samples are rarely delivered to the laboratory in three different containers according to participating MBLs. This could be explained by the possible immediate distribution of CSF samples to pertinent speciality laboratories, which are not necessarily part of the core (biochemistry) laboratory. Nevertheless, an increased risk of erroneous results, particularly in samples contaminated with large numbers of red blood cells, may be present if CSF samples are not properly labelled (16). Although relatively high mean scores for statements regarding CSF sample delivery time and the specification of type of 
puncture were obtained, poor adherence to desirable preanalytical performance by some participating MBLs was observed. Therefore, the wide implementation of harmonized preanalytical procedures in CSF sampling and transport could considerably contribute to test results' reliability. The rapid differentiation (and/or exclusion) of acute inflammatory diseases of the central nervous system (CNS) can be obtained by performing a basic workup which we suitably refer to as emergency (STAT) CSF test panel $(3,17)$. High mean scores obtained for STAT CSF analysis indicates high consistency of tests used for CSF screening. Furthermore, the majority of MBLs surveyed declared to fulfil a STAT turnaround time of one hour. CSF cell counts in Croatian MBLs are predominantly determined by traditional manual method, from native CSF samples, using a Fuchs-Rosenthal's chamber and results reported in SI units. Although both manual and automated cell counting methods are recommended by the CCMB and the latter could improve results' precision, we report rare utilization of automated methods in most participating MBLs $(7,9)$. This is expected considering the reported limitations of such methods (18). High CSF protein concentrations are a useful, although nonspecific, indicator of meningeal or CNS disease (19). Total CSF protein concentrations may be measured using several sensitive methods. The majority of the surveyed MBLs declared to use the pyrogallol red method for total CSF protein determination, which complies with the CCMB document (9). Inaccuracy and imprecision of CSF/serum quotients can be reduced only if paired serum and CSF samples are analysed within the same run, with the same analytical method and calibration curve $(20,21)$. According to survey's results, participating MBLs rarely use the same calibration curve for serum and CSF parameters in $\mathrm{Q}_{\text {Alb }}$ and $\mathrm{Q}_{\mathrm{lg}}$ calculation.

The simultaneous sampling of serum and serous fluid is necessary for reliable interpretation of serous fluid evaluations' results (i.e. no reference values for serous fluid parameters are available). However, evidence suggests that the reported sampling timing differs significantly (from "obtained simultaneously" to "within 24 hours") $(3,22)$. The paired delivery of serous and serum sample is not considered standard practice in Croatian MBLs surveyed. This is certainly a point that needs clear definition and harmonization, regardless the insufficiency of data to completely understand how the time interval between serous fluid and serum sampling affects results interpretation (23).

The majority of surveyed MBLs confirmed availability of written procedures for serous fluid analysis to laboratory staff. This implies harmonization of procedures for serous fluid evaluation within corresponding MBLs. Serous effusions are traditionally differentiated into transudates and exudates to facilitate identification of the underlying mechanisms and possible treatment options. Although nonspecific, the evaluation of serous fluid appearance is straightforward and can provide useful diagnostic information $(5,24)$. The surveyed MBLs often include appearance examination in serous fluid analysis, as suggested by the CCMB (9). Additionally, they declared to measure protein, LD and albumin in serous and serum samples, as evidenced by the favourable scores obtained for pleural, peritoneal (ascitic) and pericardial fluid. Interestingly, MBLs rarely calculate the ascites/serum protein ratio and ascites/serum LD ratio as a part of peritoneal fluid evaluation. Thus, the diagnostic accuracy of peritoneal fluid differentiation is not improved by implementation of Light's criteria into routine practice $(25,26)$. In fact, the calculation of the aforementioned ratios is not recommended by the CCMB in the section addressing peritoneal (ascitic) fluid analysis. Conversely, Light's criteria and serum-effusion albumin gradient are listed in the same CCMB document for pleural effusions' evaluation (9). The clinical decision limits stated by the CCMB are often used in Croatian MBLs for serous fluids differentiation. The lack of manufacturer's specifications for serous fluids obligates the laboratory to extensively validate method performance for their possible use with these alternative matrixes $(3,5,19)$. MBLs surveyed stated that method verification for peritoneal fluid analysis is often performed. Considering all the challenges of such verification procedures, we opine that it is more likely that the statement regarding method verification was misunderstood. Thus, the corresponding score should be interpreted with caution (i.e. 
the score probably reflects verification of methods performed for standard laboratory samples).

In 2010 the fifth edition of "WHO laboratory manual for the examination and processing of human semen" was published (27). Although not obligatory, this manual should be regarded as guideline for semen analysis. The CCMB harmonization document adopted methods and decision limits from the WHO manual issued in 1999 (9). Consequently, it should be reviewed and updated in light of new available evidence. Despite the availability of a comprehensive global guideline for seminal fluid analysis and results interpretation, our results suggest unsatisfactory harmonization of seminal fluid analysis in Croatian MBLs. The majority of surveyed Croatian MBLs have written patients' instructions on how to prepare for seminal fluid analysis. This is of utmost importance since semen collection procedures may affect usefulness and reliability of results (27). Furthermore, written procedures for seminal fluid analysis are available to laboratory staff in most surveyed MBLs. Thus, harmonization of procedures in seminal fluid analysis within the corresponding MBLs can be presumed. Semen samples should be collected near the laboratory to minimize sample exposure to temperature fluctuation and reduce time between collection and analysis (27). Our results suggest poor adherence of Croatian MBLs to this recommendation. However, the majority of MBLs surveyed stated that procedures for adequate sample delivery are instituted in their facilities, indicating the MBLs' attempt to minimize the influence of preanalytical factors on semen analysis. The majority of the surveyed MBLs analyse traditional semen parameters (e.g. appearance, volume, liquefaction etc.) of the sperm quality. Drug intake is generally not listed on test requests although drugs may influence sperm production and quality (28). In assessing sperm number and concentration, it is recommended that a total of 400 spermatozoa are counted, to obtain a sampling error of less than $5 \%$ (27). Since very low sperm numbers warrant a higher sampling error, the test report should include the calculated sampling error. Our results suggest that it is rarely reported by surveyed MBLs. The CCMB's recommended reference rang- es for seminal fluid analysis are often used in Croatian MBLs, which indicates some degree of results' interpretation harmonization. Unfortunately, these ranges are no longer valid and should be replaced with new, WHO recommended values. Seminal fluid is often used to evaluate the fertility potential of a seminal ejaculate as part of assisted reproductive procedures (29). Thus, the harmonization of seminal fluid analysis is important not only for $\mathrm{MBL}$, but for in vitro fertilization laboratories as well.

EBF, as all "standard" sample types, should be subjected to appropriate quality control procedures to ensure reliability of results and patient safety. Implementation of quality control (QC) testing is a prerequisite for the use of standard assays in EBF analysis (3). Unfortunately, quality control is a major issue in EBF testing due to scarce availability of commutable quality controls and proficiency testing materials. The respective unsatisfactory low scores obtained for CSF and seminal fluid analysis evidence this. Conversely, the majority of MBLs stated that internal QC schemes are established for specific pleural fluid analytes. It is our opinion that the high score obtained reflects QC procedures used for "standard" sample types and consequently should be interpreted with caution. The absence of suitable (i.e. matrix matched) QC materials should be addressed in future harmonization documents and if possible prompt the national proficiency testing provider to expand the existing scheme to include as many EBF analytes as possible.

Finally, interpretative comments are an important part of the postanalytical phase of laboratory testing. Adding comments to test reports, especially when complex test and/or test panels are reported, could enhance the value of laboratory information, improve their clinical applicability and ultimately patient management $(11,30)$. Laboratory testing of EBF can be considered complex for reasons that include preanalytical and analytical issues, lack of comparative values and clinician's expertise in this speciality area. Although our results suggest low laboratory professionals' awareness of the importance of interpretative commenting in EBF testing, it is our opinion that they should play 
a greater role in this respect. Current developments in laboratory technology and computer networks along with the harmonization of commenting should facilitate their use and encourage their implementation.

The limitations of our investigation should be addressed. In order to survey procedures used in laboratory testing of nine different EBF (listed in the Introduction), we designed a quite extensive questionnaire. Unfortunately, even such an extensive questionnaire enabled us to survey only selected preanalytical, analytical and postanalytical procedures of EBF laboratory testing. This has limited the comprehensiveness of obtained results. Additionally, due to low response rate, our results may not represent accurately all Croatian MBLs. Practices used in laboratory testing of EBFs most rarely analysed (synovial, amniotic fluid and sweat) were not presented nor analysed due low statistical strength. Likert scales are widely used in different fields for opinion measurement. However, their limitation is the possible response distortion resulting in central tendency, acquiescence and social desirability bias (31). These biases must be taken into consideration when interpreting results from Likert scale based surveys. Finally, data were

\section{References}

1. Wians FH. To test or not to test? Opening Pandora's box. Lab Medicine 2004;35:707. http://dx.doi.org/10.1309/3REBHJFAQVLXUQ5W.

2. Akgul M, Noguez J. Body fluid testing. What you should know before you hit go. Available at: https://www.aacc.org/ publications/cln/articles/2015/october/body-fluid-testingwhat-you-should-know-before-you-hit-go. Accessed October 25th 2015.

3. Clinical and Laboratory Standards Institute. Analysis of body fluids in clinical chemistry; Approved guideline. CLSI document C49-A, Wayne, Pennsylvania, USA, 2007.

4. BlockDR. Practical Guide to the Analytical Validation of Body Fluid Chemistry Testing. Available at: http://www.mayomedicallaboratories.com/articles/communique/2013/03bodyfluid-testing/index.html. Accessed October 25th 2015.

5. Milevoj Kopcinovic L, Culej J. Pleural, peritoneal and pericardial effusions - a biochemical approach. Biochem Med (Zagreb) 2014;24:123-137. http://dx.doi.org/10.11613/ BM.2014.014 self-reported and thus could not be verified independently.

In conclusion, our results confirm that procedures used in laboratory testing of EBF in Croatia are not harmonized. Deviations from desirable EBF laboratory testing procedures were detected in all segments of the EBF total testing process, but were found more pronounced for the following key aspects: quality control and/or proficiency testing, and interpretative commenting of EBF test results. Thus, generation of comprehensive recommendations related to EBF laboratory testing are urgently needed in Croatia. We believe that our results represent a step closer in achieving harmonization of these precious laboratory measurements in an effort to minimise misinterpretation and adverse patient outcomes.

\section{Acknowledgements}

The authors would like to thank medical biochemistry laboratories who participated in the survey.

\section{Potential conflict of interest}

None declared.
6. Clinical and Laboratory Standards Institute. Sweat testing: Sample collection and quantitative chloride analysis; Approved guideline - third edition. CLSI document C34-A3, Wayne, Pennsylvania, USA, 2009.

7. Clinical and Laboratory Standards Institute. Body fluid analysis for cellular composition: Approved guideline. CLSI document H56-A, Wayne, Pennsylvania, USA, 2006.

8. Clinical and Laboratory Standards Institute. Assessment of fetal lung maturity by the lamellar body count; Approved guideline. CLSI document C58-A, Wayne, Pennsylvania, USA, 2011.

9. Harmonizacija laboratorijskih nalaza u području opće, specijalne i visokodiferentne medicinske biokemije. Available at: http://www.hkmb.hr/obavijesti/obavijesti-index.html (in Croatian). Accessed October 12th 2015.

10. Plebani M. Harmonization in laboratory medicine: the complete picture. Clin Chem Lab Med 2013;51:741-51. http:// dx.doi.org/10.1515/cclm-2013-0075. 
11. Plebani M. Interpretative commenting: A tool for improving the laboratory-clinical interface. Clin Chim Acta 2009;404:4651. $h$ ttp://dx.doi.org/10.1016/j.cca.2009.03.012.

12. International Organization for Standardization 15189:2012: Medical laboratories: requirements for quality and competence. Geneva, Switzerland, 2012.

13. Standardi dobre stručne prakse. Sadržaj uputnice. Available at: http://www.hkmb.hr/povjerenstva/strucna-pitanja.html (in Croatian). Accessed October 17th 2015.

14. Strasinger S. Body fluid analysis. In: Bishop ML, Fody EP, Schoeff $L E$, eds. Clinical chemistry techniques, principles, correlations. 6th edition. Baltimore, MD and Philadelphia, PA: Lippincott Williams and Wilkins; 2010. p. 591-602.

15. Teunissen CE, Petzold A, Bennett JL, Berven FS, Brundin L, Comabella $M$, et al. A consensus protocol for the standardization of cerebrospinal fluid collection and biobanking. Neurology 2009;73:1914 - 22. http://dx.doi.org/10.1212/ WNL.0b013e3181c47cc2.

16. Deisenhammer F, Bartos, Egg R, Gilhus NE, Giovannoni $G$, Rauer S, et al. Routine cerebrospinal fluid (CSF) analysis. In: European Handbook of Neurological Management, 2nd edition. Blackwell Publishing, 2011. p. 5-17.

17. Regeniter A, Kuhle J, Mehling M, Möller H, Wurster U, Freidanka $H$, et al. A modern approach to CSF analysis: pathophysiology, clinical application, proof of concept and laboratory reporting. Clin Neurol Neurosurgery 2009;111:313318. http://dx.doi.org/10.1016/j.clineuro.2008.12.004.

18. Li A, Grönlund E, Brattsand G. Automated white blood cell counts in cerebrospinal fluid using the body fluid mode on the platform Sysmex XE-5000. Scand J Clin Lab Invest 2014;74:673-80. http://dx.doi.org/10.3109/00365513.2014. 939994.

19. Karcher DS, McPherson RA. Cerebrospinal, synovial, serous body fluids and alternative specimens. In: Henry's clinical diagnosis and management by laboratory methods, 22th edition. Richard A. McPherson, Matthew R. Pincus eds. Elsevier Saunders, Philadelphia (PA), 2011. p. 480-506. http://dx.doi. org/10.1016/b978-1-4377-0974-2.00029-4

20. Reiber $H$. Reporting Cerebrospinal fluid data: knowledge base and interpretation software. Available at: http://www. ifcc.org/ifcc-communications-publications-division-(cpd)/ ifcc-publications/ejifcc-(journal)/e-journal-volumes/ejifcc2004-vol-15/vol-15-n\%C2\%B0-3/reporting-cerebrospinalfluid-data-knowledge-base-and-interpretation-software/. Accessed April 1st 2016.
21. Reiber H. External quality assessment in clinical neurochemistry: survey of analysis or cerebrospinal (CSF) fluid proteins based on CSF/serum quotients. Clin Chem 1995;441:256263.

22. Heffner JE, Brown LK, Barbieri CA. Diagnostic value of tests that discriminate between exudative and transudative pleural effusions. Chest 1997; 111: 970-80. http://dx.doi. org/10.1378/chest.111.4.970.

23. Jenkinson F, Murphy MJ. Biochemical analysis of pleural and ascitic fluid: effect of sample timing on interpretation of results. Ann Clin Biochem 2007;44:471-73. http://dx.doi. org/10.1258/000456307781645978.

24. Block DR, Algeciras-Schimnich A. Body fluid analysis: Clinical utility and applicability of published studies to guide interpretation of today's laboratory testing in serous fluids. Crit Rev Clin Lab Science 2013;50:107-24. http://dx.doi.org/ 10.3109/10408363.2013.844679.

25. Tarn AC, Lapworth R. Biochemical analysis of ascetic (peritoneal) fluid: what should we measure? Ann Clin Biochem 2010;47:397-407. http://dx.doi.org/10.1258/ acb.2010.010048.

26. Burgess LJ. Biochemical analysis of pleural, peritoneal and pericardial effusions. Clin Chim Acta 2004;343:61-84. http:// dx.doi.org/10.1016/j.cccn.2004.02.002.

27. World Health Organization. WHO laboratory manual for the examination and processing of human semen. 5th ed. 2010.

28. Samplaski MK, Nangia AK. Adverse effects of common medications on male fertility. Nature Reviews Urology 2015;12:401-13. http://dx.doi.org/10.1038/nrurol.2015.145.

29. Agarwal A, Said TM. Interpretation of basic semen analysis and advanced semen testing. In: Current Clinical Urology: Male Infertility: Problems and Solutions, Edited by: Sabanegh ES, Springer Science and Business Media, 2011. http:// dx.doi.org/10.1007/978-1-60761-193-6_2.

30. Lim EM, Sikaris KA, Gill J, Calleja J, Hickman PE, Beilby J, Vasikaran SD. Quality assessment of interpretative commenting in clinical chemistry. Clin Chem 2004;50:632-37. http:// dx.doi.org/10.1373/clinchem.2003.024877.

31. Rinker T. On the treatment of Likert data. Available from: https://www.researchgate.net/publication/262011454_Likert. Accessed August 14th 2016. 